year, for a few cycles of sun-spots, the mineral conditions would be constantly varying; so that any test by the balance to compare the fruit of one year with that of another, would involve too many unappraisable elements to have a real value.

Prof. Jevons observes that his investigation is "embarrassed by the fact that no inquirer has been able to discover a clear beriodic variation in the price of corn." But the quality of periodic variation in more immediate effect of solar action than the price. Now, although perhaps not much is to be arrived at from the method suggested by Mr. Kemp, there is another direction in which something might be found, and in which the necessary data already exist. I allude to the records of those Corn Exchanges which contain full details of the measure-weight of every parcel of grain which has been sold in them for several sun-spot periods. I reduced the sales in the Haddington Corn Exchange for the year from July $3, \mathbf{1} 868$, to June 25 , 1869, and found the average bushel-weights as under:-

Wheat ... 27,764 quarters ..... 63.15 lbs. per bushel.

Barley ... 33,022 ", … 56.85 ," ,

Oats ...... 16,223 ", ..... $43^{\circ} 49$," ,

The sales in the Edinburgh Corn Exchange from November 4, a 868 , to October $27, \mathbf{1 8 6 9}$, gave the following weights:-

Wheat ... 27,322 quarters ..... 62.84 lbs. per bushel.

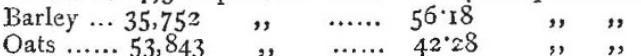

Reductions on this larger scale probably eliminate most of the elements of uncertainty. The measure-weight of the cereal grains depends on various factors, one of which is the comparative distension of the epicarp by the inclosed albumen. It is this element which may vary with variations of solar radiation. And if a cycle of measure-weight should te found corresponding with the sun-spot period, a clue might be gained to some unsuspected commercial relationship.

North Kinmundy, Aberdeen

A. Stephex WILsoN

\section{Time and Longitude}

I HAVE been much amused at the questions on the above (NATURE, vol. xviii. p. 40), by Mr. Latimer Clark, and the answer (p. 66) by my old friend Capt. J. P. Maclear; the numbers of NATURE for May having only just reached my "out-of-the-world" residence. I suspect Mr. L. C. has had in his mind what I have often had, and with which $I$ have frequently puzzled some "unco guid" Sabbatarians! If it is sucl a deadly sin to work on Sunday, one or the other of $A$ and $B$ coming, one from the east, the other from the west, of $180^{\circ}$ meridian, must, if he continues his daily avocations, be in a bad way! Some of our people in Fiji are in this unen. viable position, as the line of $180^{\circ}$ passes through Loma-Loma !

I went from Fiji to Tonga in H.M.S. Ny'mph, and arrived at our destination on Sunday, according to our reckoning from Fiji, but Monday, according to the proper computation west from Greenwich. We, however, found the natives all keeping Sunday. On my asking the missionaries about it they told me that the missions to that group and the "navigators," having all come from the castward, had determined to observe their seventh day, as usual, so as not to subject the natives to any future puzzle, and agreed to pat the dividing line further off, between them and Hawaii, somewhere in the broad ocean, where there were no metaphysical natives or "intelligent Zulus" to cross-question them!

British Consulate, Noumea, New Caledonia

\section{Hereditary Transmission}

I HAVE perused with interest Mr. Edmund Watt's account of the six-fingered family in Dominica, as it recalls to my memory a family showing precisely the same peculiarities in Ceylon, at Point Pedro, the most northerly point of the island, where, twenty-six years ago, I was magistrate.

A family quarrel came before me, and I found, to my great astonishment, that plaintiff and defendant, and all the witnesses, had six fingers on each hand and six toes on each foot! The additional finger or toe was, in each instance, a "little finger" (or toe) inserted in the side of the hand o: foot, quite loosely, adhering to the shin, and not part of the skeleton. It might easily have been excised with a pair of ordinary scissors. The parties were all closely related-brotbers and sisters, uncles and aunts, nephews, nieces, and cousins-they must have had a common progenitor. It would be essy, and most intcresting, to ascertain if any of the fanily now exist, an?, if so, if the supplementary finger has been transmitted to the present gene. ration. A note to the "Resident Magistrate," Point Pedro, would, I hope, produce a reply. If any of the family of my old clerk, Mr. Dehoedt, survive, they would recollect the fact. I think the party came from Panditerripu. E. L. LAYARD

British Consulate, Noumea

\section{"Survival of the Fittest"}

In NATURE, vol. xix. p. I55, Mr. S. F. Clarke's observations on the cannibal habits so rapidly developed by the larvæ of the New England salamanders are cited in illustration of the survival of the fittest. The fact that similar tendencies are invariably betrayed very early in life by theyoung of the common Mexican Axolotl (Siredon mexicanum), numbers of which are annually hatched out in the Brighton Aquarium, may perhaps be of interest. Many of the smaller and weaker ones are bodily devoured by their stronger brethren of the same brood, an inclina tion which is so marked that systematic over-feeding is resorted to in order to arrest the diminution in the number of specimens.

Brighton, December 27, 1878 A. CRANE

\section{Shakespeare's Colour-Names}

IN the very interesting articles and correspondence which you have published on the subject of colour-blindness, it is rathe: surprising that no one has referred to a passage which, if taken alone, would appear to show that Shakespeare did not know the difference between green and blue. In "Romeo and Juliet" (Act iii., Scene 5), the Nurse says to Juliet, speaking of Paris :"Oh, he's a lovely gentleman;

Romeo's a dish-clout to him; an eagle, madarn,

Hath not so green, so quick, so fair an eye

As Paris hath."

What is here called a green eye is evidently what we call a blue one. But Iago ("Othello," Act iii., Scene 3) calls jealousy a "green-eyed monster," using the expression "green-eyed" as a modern might use it, and meaning something very unlike "blue-eyed." These instances appear only to show that in the Ianguage of Shakespeare's time the names of colours were nsed somewhat vaguely. JOsEpH JOHN MURpHy

Old Forge, Dunmurry, co. Antrim, December 23

\section{DISCUSSION OF THE WORKING HYPOTHESIS THAT THE SO-CALLED ELEMENTS ARE} COMPOUND BODIES ${ }^{1}$

$\mathrm{T}^{\mathrm{T}}$ is known to many Fellows of the Society that $\mathrm{I}$ have

for the last four years been engaged upon the preparation of a map of the solar spectrum on a large scale, the work including a comparison of the Fraunhofer lines with those visible in the spectrum of the vapour of each of the metallic elements in the electric arc.

To give an idea of the thoroughness of the work, at all events in intention, I may state that the complete spectrum of the sun, on the scale of the working map, will be half a furlong long; that to map the metallic lines and purify the spectra in the manner which has already been described to the Society, more than 100,000 observations have been made and about two thousand photographs taken.

In some of these photographs we have vapours compared with the sun; in others vapours compared with each other; and others again have been taken to show which lines are long and which are short in the spectra.

I may state in way of reminder that the process of purification consisted in this: When, for instance, an impurity of manganese was searched for in iron, if the longest line of $\mathrm{Mn}$ was absent, the short lines must also be absent on the hypothesis that the elements are elementary; if the longest line were present, then the impurity was traced down to the shortest line present.

The Hypothesis that the Elements are Simple Bodies does not include all the Phenomena

The final reduction of the photographs of all the metallic elements in the region $39-40-$ a reduction I ${ }^{x}$ Paper reat at the Royal Sxiety, December $x z$, by J. Norman Lockjer, F.R.S. 
began in the early part of the present year, and which has accumulated during the whole periot of observation. taken six montbs, summarised all the observations of Now this reduction has shown me that the hypothesis metallic spectra compared with the Fraunhofer lines that identical lines in different spectra are due to ins-

TABLE I.-FINAL REDUCTION-IRON.

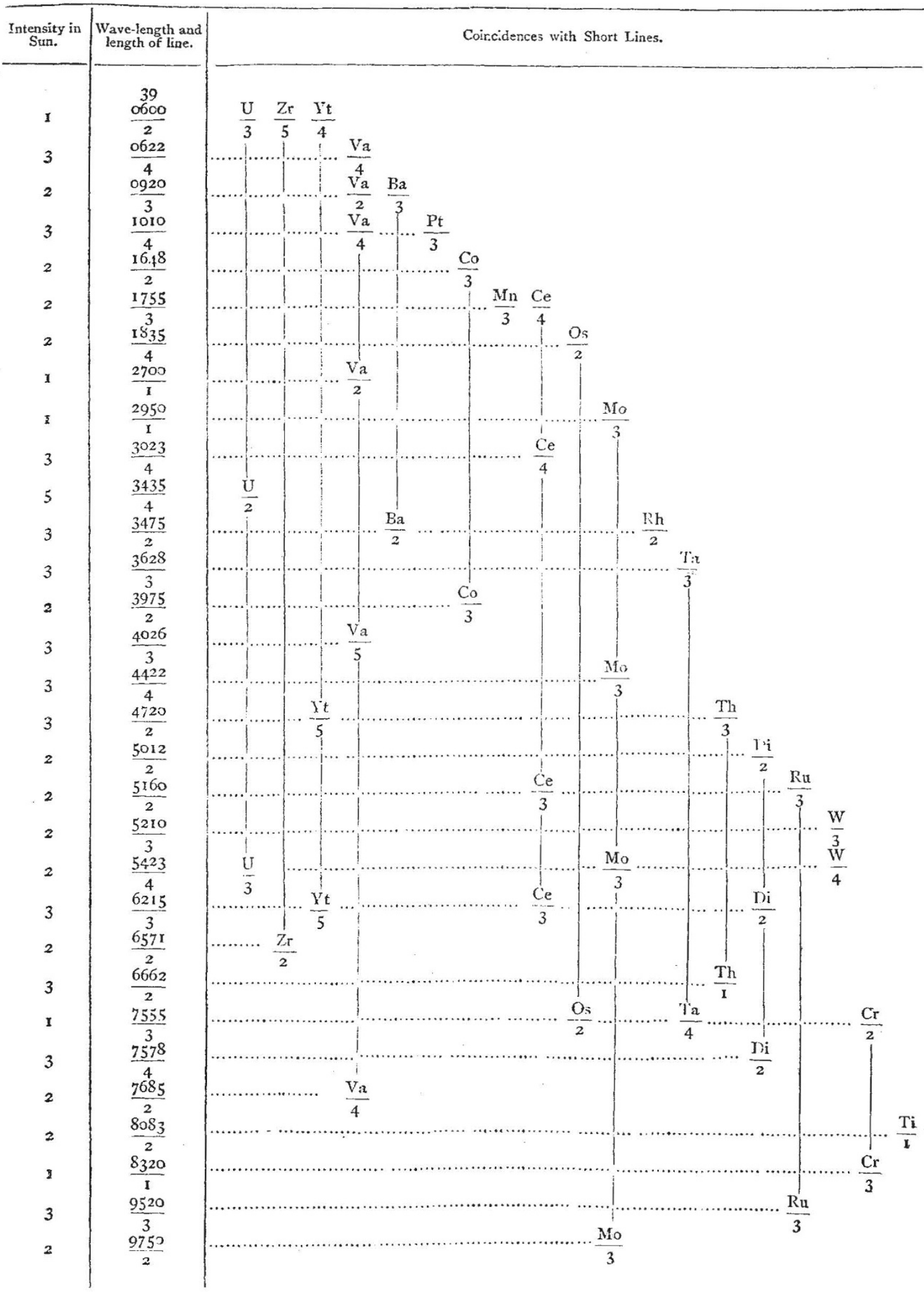


TABLE II.--FINAL REDUCTION-TITANIUM.

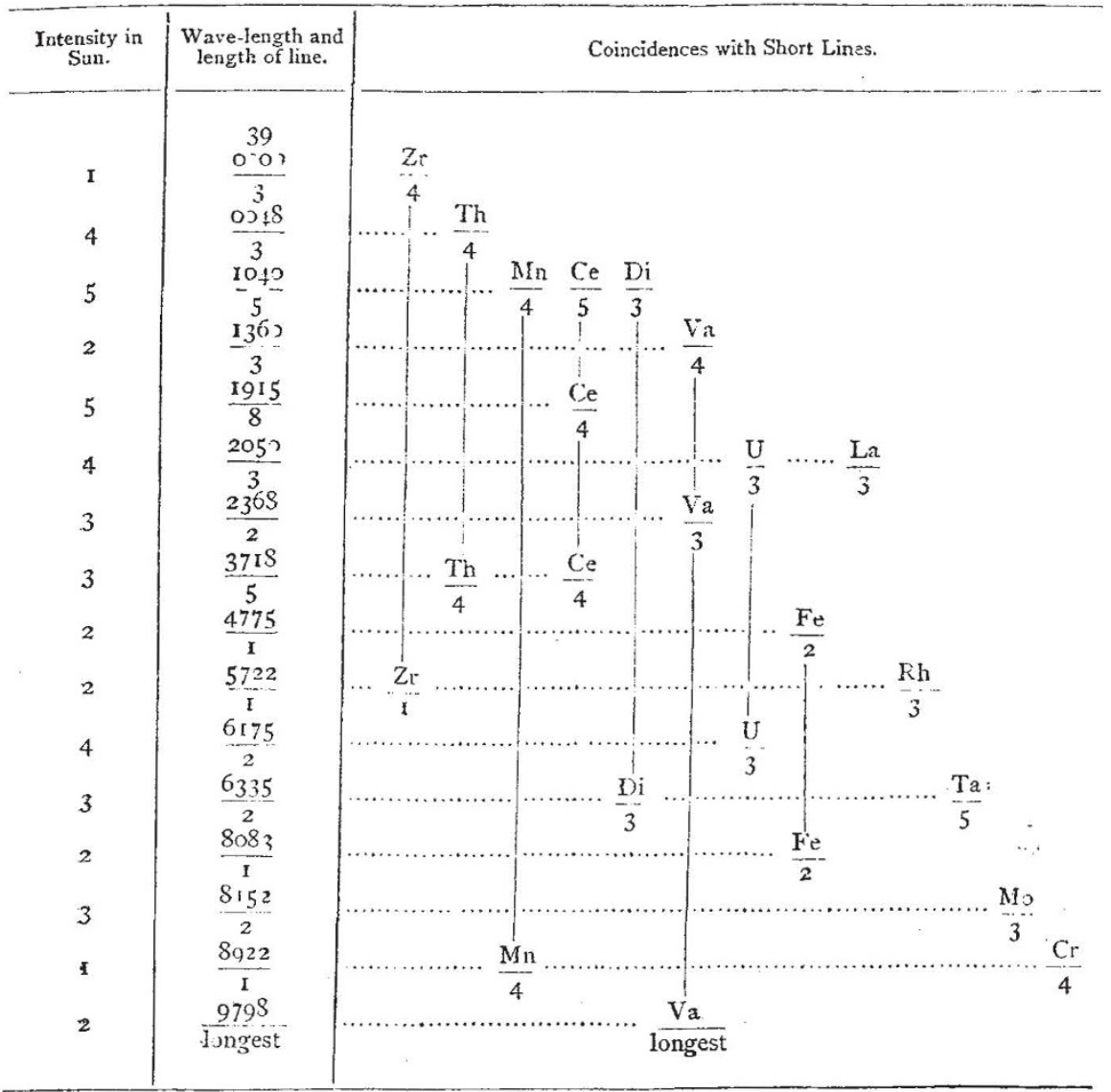

purities is not sufficient. I shall show in detail in a subsequent paper the hopeless confusion in which I have been landed. I limit myself on the present occasion to giving tables showing how the hypothesis deals with the spectra of iron and titanium.

We find short line coincidences between many metals the impurities of which have been eliminated or in which the freedom from mutual impurity has been demonstrated by the absence of the longest lines.

\section{Evidences of Celestial Dissociation}

It is five years since I first pointed out that there are many facts and many trains of thought suggested by solar and stellar physics which point to another hypothesis-namely, that the elements themselves, or at all events some of them, are compound bodies.

In a letter written to $M$. Dumas, December 3, 1873 and printed in the Comptes Rendus, I thus summarised a memoir which has since appeared in the Philosophical Transactions.

"Il semble que plus une étoile est chaude plus son spectre est simple, et que les éléments métalliques se font voir dans l'ordre de leurs poids atomiques. ${ }^{1}$

"Ainsi nous avons:

"1. Des étoiles très-brillantes où nous ne voyons que l'hyclrogène, en quantité énorme, et le magnésium.

"2. Des étoiles plus froides, comme notre Soleil, où nous trouvons :

$$
\begin{aligned}
& \mathrm{H}+\mathrm{Mg}+\mathrm{Na} \\
& \mathrm{H}+\mathrm{Mg}+\mathrm{Na}+\mathrm{Cl}, \mathrm{Fe}, \ldots ;
\end{aligned}
$$

dans ces étoiles, pas de métalloïdes;

"3. Des étoiles plus froides encore, dans lesquelles

${ }^{1}$ This referred to the cld numbers in which $\mathrm{Mg}=\mathrm{I}_{2}, \mathrm{Na}=23$. tous les éléments métalliques sont ASSOCIES, où leurs lignes ne sont plus visibles, et où nous n'avons que les spectres des métalloïdes et des composés.

"4. Plus une étoile est âgée, plus l'hydrogène libre disparaît; sur la terre, nous ne trouvons plus d'hydrogène en liberté.

"Il me semble que ces faits sont les preuves de plusieurs idées émises par vous. J'ai pensé que nous pouvions imaginer une 'dissociation céleste,' qui continue le travail de nos fourneaux, et que les métalloödes sont des composés qui sont dissociés par la température solaire, pendant que les éléments métalliques monatomiques, dont les poids atomiques sont les moindres, son précisément ceux qui résistent, même à la température des étoiles les plus chaudes."

Before I proceed further, I should state that while observations of the sun have since shown that calcium should be introduced between hydrogen and magnesium for that luminary, Dr. Huggins' photographs have demonstrated the same fact for the stars, so that in the present state of our knowledge, independent of all hypotheses, the facts may be represented as follows, the symbol indicating the spectrum in which the lines are visible.

Hottest Stars 㟧 $(\mathrm{H}+\mathrm{Ca}+\mathrm{Mg}$

Sun $\quad \ldots$ y $\mathrm{H}+\mathrm{Ca}+\mathrm{Mg}+\mathrm{Na}+\mathrm{Fe}$

Cooler Stars 音 $\{-\quad-\quad \mathrm{Mg}+\mathrm{Na}+\mathrm{Fe}+\mathrm{Bi}+\mathrm{Hg}$

Coolest

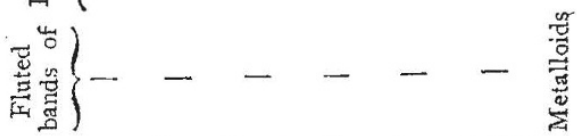

Following out these views, I some time since communi- 
cated a paper to the Society on the spectrum of calcium, to which I shall refer more expressly in the sequel.

\section{Differentiation of the Phenomena to be cbserved on the Iwo Hypotheses}

When the reductions of the observations made on metallic spectra, on the hypothesis that the elements were really elementary, had landed me in the state of utter confusion to which I have already referred, I at once made up my mind to try the other hypothesis, and therefore at once sought for a critical differentiation of the phenomena on the two hypotheses.

Obviously the first thing to be done was to inquire whether one hypothesis would explain these short line coincidences which remained after the reduction of all the observations on the other. Calling for simplicity' sake the short lines common to many spectra basic lines, the new hypothesis, to be of any value, should present us with a state of things in which basic molecules representing bases of the so-called elements should give us their lines, varying in intensity from one condition to another, the conditions representing various compoundings.

Suppose A to contain B as an impurity and as an element, what will be the difference in the spectroscopic result?

A in both cases will have a spectrum of its own;

$B$ as an impurity will add its lines according to the amount of impurity, as I have shown in previous papers.

$B$ as an element will add its lines according to the amount of dissociation, as I have also shown.

The difference in the phenomena, therefore, will be that, with gradually increasing temperature, the spectrum of A will fade, if it be a compound body, as it will be increasingly dissociated, and it will not fade if it be a simple one.

Again, on the hypothesis that $A$ is a compound body, that is, one compounded of at least two similar or dissimilar molecular groupings, then the longest lines at one temperature will not be the longest at another, the whole fabric of "impurity elimination," based upon the assumed single molecular grouping, falls to pieces, and the origin of the basic lines is at once evident.

This may be rendered clearer by some general considerations of another order.

\section{Genteral Conisiderations}

Let us assume a series of furnaces A . . . D, of which $A$ is the hottest.

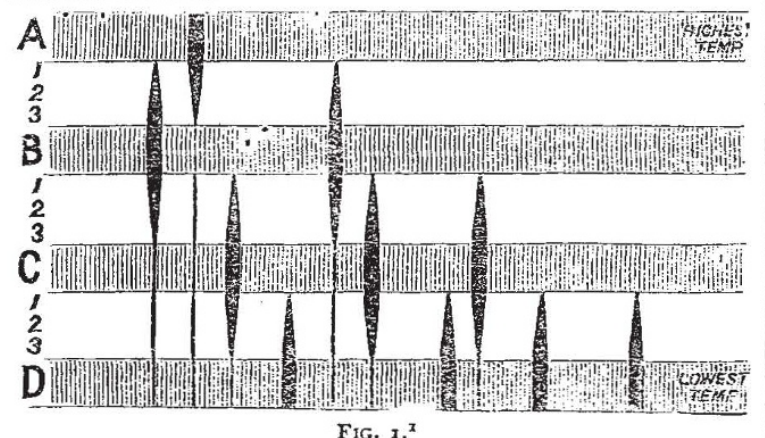

Let us further assume that in A there exists a substance $a$ by itself competent to form a compound body $\beta$ by union with itself or with something else when the temperature is lowered.

Then we may imagine a furnace $B$ in which this compound body exists alone. The spectrum of the compound $\beta$ would be the only one visible in $B$, as the spectrum of the assumed elementary body $a$ would be the only one visible in $\mathrm{A}$.

A lower temperature furnace $\mathrm{C}$ will provide us with

I The figures between the hypothetical spectra point to the gradual change as the spectrum is observed near the temperature of each of the furnaces. a more compound substance $\%$, and the same considerations will hold good.

Now if into the furnace A we throw some of this doubly compounded body $\gamma$ we shall get at first an integration of the three spectra to which I have drawn attention; the lines of $\gamma$ will first be thickest, then those of $\beta$, and finally $a$ would exist alone, and the spectrum would be reduced to one of the utmost simplicity.

This is not the only conclusion to be drawn from these considerations. Although we have by hypothesis $\beta, \gamma$, and $\delta$ all higher, that is, more compound forms of $a$, and although the strong lines in the diagram may represent the true spectra of these substances in the furnaces $B, C$, and $\mathrm{D}$, respectively, yet, in consequence of incomplete dissociation, the strong lines of $\beta$ will be seen in furnace $C$, and the strong lines of $\gamma$ will be seen in furnace $D$, all as thin lines. Thus, although in $C$ we have no line which is not represented in $D$, the intensities of the lines in $C$ and $\mathrm{D}$ are entirely changed.

In short, the line of $a$ strong in $\mathrm{A}$ is basic in $\mathrm{B}, \mathrm{C}$, and $D$, the lines of $\beta$ strong in $B$ are basic in $C$ and $D$, and so on.

I have prepared another diagram which represents the facts on the supposition that the furnace $A$, instead of having a temperature sufficient to dissociate $\beta, \gamma$, and \& into $a$ is far below that stage, although higher than $B$.

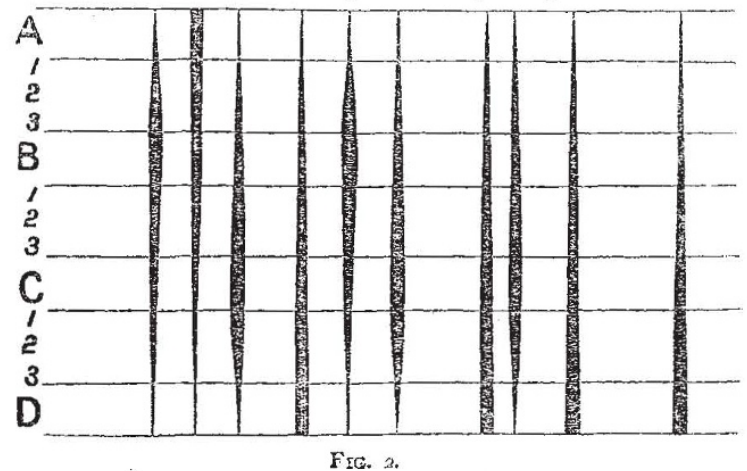

It will be seen from this diagram that then the only difference in the spectra of the bodies existing in the four furnaces would consist merely in the relative thicknesses of the lines. The spectrum of the substances as they exist in A would contain as many lines as would the spectrum of the substances as they exist in $\mathrm{D}$; each line would in turn be basic in tile whole series of furnaces instead of in one or two only.

Application of these Gencral Considerations to Impurity Elinination

Now let us suppose that in the last diagram (Fig. 2) the four furnaces represent the spectra of say, iron, broken up into different finenesses by successive stages of heat. It is first of all abundantly clear that the relative thicknesses of the iron lines observed will vary according as the temperature resembles that of $\mathrm{A}, \mathrm{B}, \mathrm{C}$, or $\mathrm{D}$. The positions in the spectra will be the same, but the intensities will vary; this is the point. The longest lines, represented in the diagram by the thickest ones, will vary as we pass from one temperature to another. It is on this ground that I have before stated that the whole fabric of impurity elimination must fall to pieces on such an hypothesis. Let us suppose, for instance, that manganese is a compound of the form of iron represented in furnace B, with something else; and suppose again that the photograph of iron which I compare with manganese represents the spectrum of the vapour at the temperature of the furnace $D$. To eliminate the impurity of iron in manganese, as I have eliminated it, we begin the search by looking for the longest and strongest lines shown in the photograph of iron, in the photograph of manganese taken under the same conditions. I do not find these lines. I 
say, therefore, that there is no impurity of iron in manganese, but although the longest iron lines are not there, some of the fainter basic ones are. This 1 hold to be the explanation of the apparent confusion in which we are landed on the supposition that the elements are elementary.

\section{Application of these Considerations to Known Compounds}

Now to apply this reasoning to the dissociation of a known compound body into its elements-

A compound body, such as a salt of calcium, has as definite a spectrum as a simple one; but while the spectrum of the metal itself consists of lines, the number and thickness of some of which increase with increased quantity, the spectrum of the compound consists in the main of channelled spaces and bands, which increase in like manner.

In short, the molecules of a simple body and a compound one are affected in the same manner by quantity in so far as their spectra are concerned ; in other words, both spectra have their long and short lines, the lines in the spectrum of the element being represented by bands or fluted lines in the spectrum of the compound; and in each case the greatest simplicity of the spectrum depends upon the smallest quantity, and the greatest complexity (a continuous spectrum) upon the greatest.

The heat required to act upon such a compound as a salt of calcium so as to render its spectrum visible, dissociates the compound according to its volatility; the number of true metallic lines which thus appear is a measure of the quantity of the metal resulting from the dissociation, and as the metal lines increase in number, the compound bands thin out.

I have shown in previous papers how we have been led to the conclusion that binary compounds have spectra of their own, and how this idea has been established by considerations having for a basis the observations of the long and short lines.

It is absolutely similar obzervations and similar reasoning which I have to bring forward in discussing the compound nature of the chemical elements themselves.

In a paper communicated to the Royal Society in 1874 , referring, among other matters, to the reversal of some lines in the solar spectrum, I remarked ${ }^{1}$ :-

"It is obvious that greater attention will have to be given to the precise character as well as to the position of each of the Fraunhofer lines, in the thickness of which I bave already observed several anomalies. I may refer more particularly at present to the two $\mathrm{H}$ lines 3933 and 3968 belonging to calcium, which are much thicker in all photographs of the solar spectrum [I might have added that they were by far the thickest lines in the solar spectrum? than the largest calcium line of this region (4226.3), this latter being invariably thicker than the $H$ lines in all photographs of the calcium spectrum, and remaining, moreover, visible in the spectrum of substances containing calcium in such small quantities as not to show any traces of the $\mathrm{H}$ lines.

"How far this and similar variations between photographic records and the solar spectrum are due to causes incident to the photographic record itself, or to variations in the intensities of the various molecular vibrations under solar and terrestrial conditions, are questions which up to the. present time I have been unable to discuss."

\section{An Objection Discussed}

I was careful at the very commencement of this paper to point out that the conclusions I have advanced are based upon the analogies furnished by those bodies which, by common consent and beyond cavil and discussion are compound bodies. Indeed, had I not been careful to urge this point the remark might have been made that the various changes in the spectra to which I shall draw

$$
\text { I Phil. Trans, vul. clxiv., part 2, p. } 807 \text {. }
$$

attention are not the results of successive dissociations, but are effects due to putting the same mass into different kinds of vibration or of producing the vibration in different ways. Thus the many high notes, both true and false, which can be produced out of a bell with or without its fundamental one, might have been put forward as analogous with those spectral lines which are produced at different degrees of temperature with or without the line, due to each substance when vibrating visibly with the lowest temperature. To this argument, however, if it were brought forward, the reply would be that it proves too much. If it demonstrates that the $h$ hydrogen line in the sun is produced by the same molecular grouping of hydrogen as that which gives us two green lines only when the weakest possible spark is taken in hydrogen inclosed in a large glass globe, it also proves that calcium is identical with its salts. For we can get the spectrum of any of the salts alone without its common base, calcium, as we can get the green lines of hydrogen without the red one.

I submit, therefore, that the argument founded on the overnotes of a sounding body, such as a bell, cannot be urged by any one who believes in the existence of any compound bodies at all, because there is no spectroscopic break between acknowledged compounds and the supposed elementary bodies. The spectroscopic differences between calcium itself at different temperatures is, as I shall show, as great as when we pass from known compounds of calcium to calcium itself. There is a perfect continuity of phenomena from one end of the scale of temperature to the other.

Inquiry into the Probable Arrangement of the Basic Molecules

As the results obtained from the above considerations seemed to be so far satisfactory, inasmuch as they at once furnished an explanation of the basic lines actually observed, the inquiry seemed worthy of being carried to.a further stage.

The next point I considered was to obtain a clear mental view of the manner in"which, on the principle of evolution, various bases might now be formed, and then become basic themselves.

It did not seem unnatural that the bases should increase their complexity by a process of continual multiplication, the factor being 1,2 , or even 3 , if conditions were avail able under which the temperature of their environment should decrease, as we imagined it to do from the furnace A down to furnace $D$. This would bring about a condition of molecular complexity in which the proportion of the molecular weight of a substance so produced in a combination with another substance would go on continually increasing.

Another method of increasing molecular complexity would be represented by the addition of molecules of different origins. Representing the first method by $A+A$, we could represent the second by $A+B$. A variation of the last process would consist in a still further complexity being brought about by the addition of another molecule of $\mathrm{B}$, so that instead of $(\mathrm{A}+\mathrm{B})_{2}$ merely, we should have $\mathrm{A}+\mathrm{B}_{2}$.

Of these three processes the first one seemed that which it was possible to attack under the best conditions, because the consideration of impurities was eliminated; the prior work has left no doubt upon the mind about such and such lines being due to calcium, others to iron, and so forth. That is to say, they are visible in the spectra of these substances as a rule. The inquiry took this form: Granting that these lines are special to such and such a substance, does each become basic in turn as the temperature is changed?

I therefore began the search by reviewing the evidence concerning calcium and seeing if hydrogen, iron, and lithium behaved in the same way.

(To be continued.) 